\title{
Testing and treatment for obstructive sleep apnea in Canada: funding models must change
}

\author{
Sachin R. Pendharkar MD MSc, Marcus Povitz MD MSc, Nick Bansback PhD, Charles F.P. George MD, \\ Debra Morrison MD, Najib T. Ayas MD MPH; for the Canadian Sleep and Circadian Network
}

Cite as: CMAJ 2017 December 11;189:E1524-8. doi: 10.1503/cmaj.170393

See related article at www.cmaj.ca/lookup/doi/10.1503/cmaj.170296

$\mathbf{T}$ he Public Health Agency of Canada has estimated that a quarter of adult Canadians are at risk for obstructive sleep apnea (OSA). ${ }^{1}$ Despite a large potential disease burden, insufficient public funding for sleep diagnostic testing and treatment of OSA in most of Canada leads to underdiagnosis and undertreatment. ${ }^{2}$ There is a mix of reimbursement models across provinces, ranging from almost complete public funding to mostly private care of patients with OSA; consequently, the way that Canadians with suspected OSA obtain care differs substantially based on province of residence and financial means. This interprovincial and interindividual variability leads to differential access to diagnostic testing, particularly for low-income or rural populations. Furthermore, the lack of government funding in several provinces prevents many patients from accessing treatment that is known to improve clinical outcomes and is costeffective. Overall, the current system of funding for OSA care contributes to suboptimal care that is not equitable, accessible or patient centred.

The burden of OSA is substantial and associated with important adverse health effects, including cardiovascular disease, depression, neurocognitive changes, reduced work productivity and occupational injuries. ${ }^{3}$ Drivers with untreated OSA are at increased risk of motor vehicle crashes, highlighting public safety implications that extend beyond the patient. ${ }^{4}$ Treatments for which there is evidence of effectiveness in symptomatic and asymptomatic patients include continuous positive airway pressure and oral appliances. ${ }^{3} \mathrm{~A}$ recent independent Canadian health technology assessment concluded that treatment of moderate to severe OSA is cost-effective, with incremental cost-utility ratios of $\$ 7420-\$ 43899$ depending on choice of therapy and severity of OSA, ${ }^{5}$ which matches results from other countries. ${ }^{6}$

The gold standard for assessing OSA includes referral to a sleep physician followed by in-laboratory polysomnography for diagnosis and start of treatment according to Canadian Thoracic Society guidelines. ${ }^{7}$ Among Canadian provinces, Ontario uses this model, publicly funding many sleep laboratories and a relatively large number of sleep specialists. In contrast, elsewhere in Canada, limited public funding of sleep laboratories has led to

\section{KEY POINTS}

- Obstructive sleep apnea (OSA) is highly prevalent and associated with important adverse individual and public health outcomes.

- Inadequate public funding for both sleep diagnostic testing and cost-effective treatments for OSA has resulted in a strong reliance on privately funded care in most Canadian provinces, which has led to inequities in access to care based on patients' financial means and place of residence.

- Evidence-based treatment of OSA has been shown to be costeffective, but current models of providing testing and treatment prevent patients from benefiting from cost-effective care.

- Stronger regulations are required to protect patients from potential conflicts of interest inherent in the delivery of diagnostic and treatment services by private vendors.

lengthy wait times for in-laboratory polysomnography and the adoption of sleep apnea testing at home. The latter approach has some limitations, although in randomized controlled trials involving patients with moderate to high pretest probability of OSA, it has been shown to be noninferior to polysomnography-based care. ${ }^{8,9}$ Most studies excluded patients with cardiopulmonary comorbidity or suspicion of another concomitant sleep disorder, who typically require polysomnography. ${ }^{10}$ And, despite good diagnostic performance of sleep apnea testing at home, the modest rates of false-negative testing and technical failure necessitate access to polysomnography for some patients to ensure accurate diagnosis. ${ }^{3}$ Models that incorporate both home sleep apnea testing and in-laboratory testing are cost-effective..$^{11,12}$

Home sleep apnea testing is offered through the public system in some instances, but there are usually long waiting lists (often many months) for patients with suspected OSA to be evaluated by a sleep specialist. ${ }^{13-15}$ Many family physicians and nonsleep specialists turn to private vendors to perform both diagnostic testing in patients with suspected OSA and initiation of continuous positive airway pressure in those who require treatment. Less than $5 \%$ of Canadians have been referred for sleep laboratory testing, and 
despite a high prevalence of at-risk individuals (26\%), only $3 \%$ have received a diagnosis of OSA. ${ }^{2}$ It is difficult to quantify referrals to private vendors, but we estimate that outside of Ontario, between $20 \%$ and $80 \%$ of patients with suspected OSA seek private care, with a higher use of private health care in provinces with less public funding for OSA testing and treatment.

Treatment of OSA with continuous positive airway pressure or oral appliances carries an initial cost and, in the case of continuous positive airway pressure, additional costs every 6 to 12 months for replacement masks and tubing, which can be prohibitive for many. Furthermore, continuous positive airway pressure machines typically require replacement every 5 to 10 years, while the lifespan of an oral appliance is between 2 and 10 years. Costs for beginning treatment and provincial and territorial funding models are outlined in Table 1. Although there are subsidy programs for some patients, this funding typically excludes oral appliances.

Table 1: Funding models for obstructive sleep apnea therapy across Canada*

\begin{tabular}{|c|c|c|}
\hline $\begin{array}{l}\text { Province/ } \\
\text { Territories }\end{array}$ & Funding model $†$ & $\begin{array}{c}\text { Approximate initial cost } \\
\text { of treatment }\end{array}$ \\
\hline \multirow[t]{2}{*}{ British Columbia } & Private & CPAP: $\$ 1800-\$ 2500$ \\
\hline & & OA: $\$ 400-\$ 2800$ \\
\hline \multirow[t]{2}{*}{ Alberta } & Private & CPAP: $\$ 1500-\$ 2800$ \\
\hline & & OA: $\$ 300-\$ 3000$ \\
\hline \multirow[t]{2}{*}{ Saskatchewan } & $\begin{array}{l}\text { Mixed public and } \\
\text { private }\end{array}$ & $\begin{array}{l}\text { CPAP: } \$ 1750-\$ 2500 \\
\text { (private); } \$ 500-\$ 600 \\
\text { (public) } \ddagger\end{array}$ \\
\hline & & OA: $\$ 1750-\$ 2000$ \\
\hline \multirow[t]{2}{*}{ Manitoba } & $\begin{array}{l}\text { Mixed public and } \\
\text { private }\end{array}$ & $\begin{array}{l}\text { CPAP: } \$ 1175 \text { (100\% public } \\
\text { coverage) }\end{array}$ \\
\hline & & OA: $\$ 1200-\$ 3000$ \\
\hline \multirow[t]{2}{*}{ Ontario } & $\begin{array}{l}\text { Mixed public and } \\
\text { private }\end{array}$ & $\begin{array}{l}\text { CPAP: } \$ 1000-\$ 1200 \text { (\$645 } \\
\text { public coverage)§ }\end{array}$ \\
\hline & & OA: $\$ 1200-\$ 3000$ \\
\hline \multirow[t]{2}{*}{ Quebec } & Private & CPAP: $\$ 1500-2500$ \\
\hline & & OA: $\$ 2000-\$ 3000$ \\
\hline \multirow[t]{2}{*}{ Atlantic Canada } & Private & CPAP: $\$ 1500-\$ 2500$ \\
\hline & & OA: \$865-\$2500 \\
\hline \multirow[t]{2}{*}{ Territories } & $\begin{array}{l}\text { Mixed public and } \\
\text { private }\end{array}$ & CPAP: $\$ 2000-\$ 2400$ \\
\hline & & OA: $\$ 1000-\$ 1500$ \\
\hline \multicolumn{3}{|c|}{$\begin{array}{l}\text { Note: CPAP = continuous positive airway pressure, OA = oral appliance. } \\
\text { *Figures obtained from members of the Canadian Thoracic Society Sleep Disordered } \\
\text { Breathing Clinical Assembly (British Columbia, Saskatchewan, Manitoba, Quebec) and } \\
\text { from dentists and private vendors (Alberta, Ontario, Atlantic Canada, territories). } \\
\text { tFunding model descriptions do not include government subsidy programs for } \\
\text { low-income or Indigenous patients. } \\
\text { fUntil Oct. 1, 2017, Saskatchewan Aids to Independent Living provided CPAP } \\
\text { machines at no charge, but the patient paid for masks/tubing (costs shown here); the } \\
\text { policy is currently under renegotiation, with funding limited to patients with moderate } \\
\text { to severe obstructive sleep apnea. } \\
\text { \$Public coverage includes } 75 \% \text { of cost of CPAP and basic mask; the remaining } 25 \% \\
\text { and costs for advanced masks are paid by the patient. }\end{array}$} \\
\hline
\end{tabular}

\section{What is the problem with current funding models in Canada?}

Three important problems arise from Canada's current patchwork system of public and private care for OSA: barriers to diagnosis, inequities in access to treatment and potential conflicts of interest.

\section{Barriers to diagnosis}

Long waits in the public system have been previously described in many jurisdictions, arising from the limited capacity of polysomnography facilities and supply of sleep specialists. ${ }^{13-15}$ Patients in rural and remote areas - shown in a recent observational study to have more severe OSA upon presentation to a sleep clinic $^{16}$ - must often also travel to urban centres for testing, which adds additional financial burdens of travel and overnight accommodations. Although privately funded home sleep apnea testing may help to improve access to testing in rural areas, the cost for testing could be prohibitive for some patients. We believe that the lack of public funding for diagnostic testing in some jurisdictions is likely a strong contributing factor to underdiagnosis of OSA in Canada. ${ }^{2}$ Although other factors may play a role in access to specialists, such as the requirements for sleep training and the geographic distribution of physicians, the lack of funding differentiates sleep medicine from other specialties that incorporate publicly funded procedures or diagnostic testing as part of clinical practice. Two recent non-Canadian studies have drawn attention to the role of primary care physicians in the diagnosis and treatment of OSA:17,18 however, in both studies, sleep specialist physicians interpreted sleep tests and were available for consultation when needed. Given the adverse health and public safety effects of untreated OSA, the inability to obtain a timely diagnosis of OSA because of inadequate funding of specialists is a serious concern.

\section{Inequities in access to treatment}

Patients must often bear the costs of treatment for OSA, usually through a private company that offers initiation of continuous positive airway pressure or a dentist for oral appliance therapy. The costs of these treatments may be prohibitive in the absence of third-party insurance coverage. Although a recent analysis of administrative data from Ontario did not find a statistically significant relationship between neighbourhood income and likelihood of purchasing a continuous positive airway pressure device, patients from the lowest neighbourhood income quintile were $27 \%$ less likely to purchase such a device than those from higherincome quintiles. ${ }^{19}$ Importantly, the copayment in Ontario (25\%) is lower than that used in an earlier study, which showed an association between household income and purchase of a continuous positive airway pressure device. ${ }^{20}$ Although there are many reasons why a patient may choose not to pursue therapy for OSA, it is possible that prohibitive treatment costs could lead to patients avoiding necessary OSA treatment, as has been reported for other chronic diseases. ${ }^{21,22}$ In the 1990s, the Alberta government funded a comprehensive continuous positive airway pressure program that led to high rates of adherence to therapy; ${ }^{23}$ unfortunately, there was no subsequent evaluation of OSA outcomes after the pilot ended. Some provincial health insurance plans cover contin- 
uous positive airway pressure device costs for individuals who are on disability or other social assistance programs, those below provincial low-income thresholds, and those from certain demographic groups (i.e., Indigenous populations, older people), if certain clinical criteria are met. Such programs limit patient choice by not covering therapy with oral appliances, which may negatively affect access to effective treatment for the subset of patients who do not tolerate continuous positive airway pressure. Yet surgical therapies, which are supported by limited evidence in highly selected patients, are publicly funded.

$A$ recent Canadian health technology assessment concluded that the benefits of treatment of moderate to severe OSA are worth the costs; ${ }^{5}$ thus, a model of care that relies on patients to bear the costs of treatment exposes those who do not have the ability to pay (or willingness to pay) to poorer outcomes and increased use of health care resources. A related concern arising from the lack of public funding for OSA therapy is the variability in cost for continuous positive airway pressure or oral appliances across provinces (Table 1). Patients living in different parts of Canada face treatment costs that are driven largely by local market forces rather than government-negotiated prices; consequently, costs for OSA therapy in both the public and private sectors are likely to be higher, as has been suggested for pharmaceuticals. ${ }^{24}$

\section{Conflict of interest}

Whenever the same provider administers diagnostic testing and treatments, a potential for conflict of interest arises. Lack of adequate public funding for diagnosis by a sleep specialist often leads referring physicians to rely on private companies - for whom continuous positive airway pressure device sales represent a substantial source of revenue - for access to timely diagnosis and treatment of OSA. Such a model makes patients vulnerable to providers who offer testing but who also have a financial interest in delivering treatment. For example, continuous positive airway pressure is usually not indicated for patients with mild asymptomatic OSA; ${ }^{3}$ however, it is likely in the financial interests of a private provider to offer treatment that may be marginally effective. Providers may also try to "upsell," encouraging patients to purchase more expensive devices that are not indicated (e.g., bilevel devices or adaptive servo ventilation), or may simply not offer other therapies that might be effective, better tolerated and less costly, such as an oral appliance.

Physicians are meant to oversee the process, but those who are not sleep specialists often lack the expertise to manage OSA confidently. ${ }^{25}$ Although the College of Physicians and Surgeons of Ontario has strict rules that prevent licensed treatment vendors from performing polysomnography, most provinces lack regulation that oversees the simultaneous provision of diagnostic sleep testing and treatment.

Private vendors clearly play a vital role in OSA care. Many vendors provide excellent services, including providing patient education, supporting patients to improve adherence to therapy and helping to secure funding from insurance or government programs as applicable; these are crucial in an environment of limited public funding. However, in the absence of adequate regulatory standards, there is a risk that patients will be subjected to inappropriate and costly care.

\section{How does Canada's system of funding compare internationally?}

In the United States, $80 \%$ of the cost of sleep diagnostic testing is covered by the Centers for Medicare and Medicaid Services ${ }^{26}$ and many private insurers also cover the cost of testing. Continuous positive airway pressure or oral appliance therapy is provided through durable medical equipment providers; to qualify for public funding, the provider must not have administered the test. ${ }^{27}$

Australian Medicare covers at least $75 \%$ of the cost of polysomnography services (in-laboratory or in-home) but home sleep apnea testing remains privately funded. ${ }^{28}$ As in many Canadian provinces, private vendors, including pharmacies, provide home testing and continuous positive airway pressure device sales. In the United Kingdom and New Zealand, there is similarly a mix of public and private funding for sleep care, whereas the Spanish and French governments provide public funding for continuous positive airway pressure device therapy.

Evaluations of funding models for OSA care as they relate to patient outcomes are lacking. Quality and ethical concerns related to inadequate public delivery of sleep services have been highlighted in many countries. ${ }^{29-31}$

\section{How should Canada amend its policies?}

A summary of our suggestions for improving funding of OSA care in Canada is provided in Box 1 . Because testing and appropriate treatment of OSA has been shown to be cost-effective, ${ }^{5}$ ensuring more widespread public funding for both in-laboratory polysomnography and home sleep apnea testing would be good policy to bring sleep diagnostic testing into line with other essential diag-

Box 1: Our suggestions for improving funding of obstructive sleep apnea (OSA) care in Canada

- Increase public funding for diagnostic testing

- Include both polysomnography and home sleep apnea testing to ensure appropriate use of testing based on clinical factors and test performance

- Incorporate clinical criteria into funding models to tailor selection of testing modality to individual patient characteristics

- Increase public reimbursement for treatments of OSA

- Incorporate patient preferences to improve adherence

- Use provincial or territorial contracts to lower per-patient costs

- Incorporate clinical response and adherence into funding models

- Establish regulatory standards prohibiting simultaneous provision of sleep diagnostic testing and treatment of OSA

- Engage multiple health professional stakeholders who play different roles in care delivery for patients with OSA

- Link public reimbursement for testing and treatment to regulatory standards

- Evaluate effects of increased public funding for OSA care

- Consider both interprovincial and international funding models

- Engage clinical societies, researchers and patients in setting priorities for OSA care 
nostic procedures such as endoscopy or diagnostic imaging. Although implementing publicly funded testing for a disease of such potentially high prevalence as OSA could impose a substantial burden on provincial health budgets, it is reasonable that funding for testing be tied to evidence-based clinical criteria that include the pretest probability of OSA. Development and implementation of such criteria would limit unnecessary testing and tailor the selection of a sleep test to an individual patient's risk and place of residence. Public reimbursement for sleep diagnostic testing may also attract sleep physicians to geographic areas of need, providing support to primary care physicians who currently bear the burden of management of patients with OSA and other sleep disorders.

Public reimbursement for cost-effective treatment of moderate to severe OSA would provide more equitable access to patients with a disease that has important clinical and quality-of-life consequences and would likely improve adherence to treatment. Appropriate use of public funds for treating OSA could be ensured by linking funding to clinical response and adherence to treatment. When developing funding policy, taking patient preferences for continuous positive airway pressure or oral appliances into consideration may improve outcomes if treatment choice results in better treatment adherence, as some studies have suggested..$^{32,33}$ Under a funded program, provincial (or even cross-provincial) contracts with device manufacturers and private companies could reduce per-patient costs of treatment through large volume pricing, as has been suggested by advocates for a national pharmacare strategy for Canada. ${ }^{24}$

It is essential to establish regulatory standards that would prohibit or limit simultaneous provision of testing and treatment to protect patients from potential conflicts of interest, reduce lowvalue care and preserve scarce health care dollars. Along with increased funding for testing, which could reduce the mismatch between demand and capacity for diagnosing OSA, regulatory standards would clarify the important role that vendors play in managing OSA. Linking public reimbursement for continuous positive airway pressure or oral appliances to these standards would raise the quality of care for Canadians who seek treatment for OSA. The development of regulatory standards will not be an easy task and will require participation from medical, surgical, respiratory therapy, dental and other health professional stakeholders who play a role in the delivery of care for patients with OSA in Canada.

\section{Conclusion}

Current funding models for sleep diagnostic testing and treatment of OSA in most provinces in Canada have put many patients in the position of having to make a decision to pursue care based partially on their financial means rather than solely on clinical need. We believe this reflects a failure to consider diagnosis and treatment of OSA as "medically necessary," which may in turn reflect a lack of understanding about the burden of this disease and its consequences for health. Increased public funding of diagnostic sleep testing, treatment of OSA and regulation is required to improve access to necessary, cost-effective care for patients with OSA in Canada.

\section{References}

1. Fast facts from the 2009 Canadian community health survey - sleep apnea rapid response. Ottawa: Public Health Agency of Canada; 2010. Available: www.phac-aspc.gc.ca/cd-mc/sleepapnea-apneesommeil/pdf/sleep-apnea.pdf (accessed 2017 Apr. 3).

2. Evans J, Skomro R, Driver H, et al. Sleep laboratory test referrals in Canada: sleep apnea rapid response survey. Can Respir J 2014;21:e4-10.

3. Laratta CR, Ayas NT, Povitz M, et al. Diagnosis and treatment of obstructive sleep apnea in adults. CMAJ 2017;189:E1481-8.

4. Karimi M, Hedner J, Häbel $\mathrm{H}$, et al. Sleep apnea-related risk of motor vehicle accidents is reduced by continuous positive airway pressure: Swedish Traffic Accident Registry data. Sleep 2015;38:341-9.

5. Interventions for the treatment of obstructive sleep apnea in adults: a health technology assessment. CADTH optimal use report, Vol. 6, No. 1b. Ottawa: Canadian Agency for Drugs and Technologies in Health (CADTH); 2017. Available: https://www.cadth.ca/interventions-obstructive-sleep-apnea (accessed 2017 Aug. 29).

6. Continuous positive airway pressure for the treatment of obstructive sleep apnoea/hypopnoea syndrome. Technology appraisal guidance [TA139]. London (UK): National Institute for Health and Clinical Excellence (NICE); 2008. Available: https://www.nice.org.uk/guidance/ta139 (accessed 2017 Aug. 30).

7. Fleetham J, Ayas N, Bradley D, et al. Canadian Thoracic Society 2001 guideline update: diagnosis and treatment of sleep disordered breathing. Can Respir $J$ 2011;18:25-47.

8. Corral J, Sanchez-Quiroga M, Carmona-Bernal C, et al. Conventional polysomnography is not necessary for the management of most patients with suspected obstructive sleep apnea. Am J Respir Crit Care Med 2017 June 21 [Epub ahead of print]. doi:10.1164/rccm.201612-24970C.

9. Kuna ST, Gurubhagavatula I, Maislin G, et al. Noninferiority of functional outcome in ambulatory management of obstructive sleep apnea. Am J Respir Crit Care Med 2011;183:1238-44.

10. El Shayeb M, Topfer L, Safinski T, et al. Diagnostic accuracy of level 3 portable sleep tests versus level 1 polysomnography for sleep-disordered breathing: a systematic review and meta-analysis. CMAJ 2014;186:E25-51.

11. Masa JF, Corral J, Sanchez de Cos J, et al. Effectiveness of three sleep apnea management alternatives. Sleep 2013;36:1799-807.

12. Stewart SA, Penz E, Fenton M, et al. Investigating cost implications of incorporating level III at-home testing into a polysomnography based sleep medicine program using administrative data. Can Respir J 2017;2017:8939461.

13. Flemons WW, Douglas NJ, Kuna ST, et al. Access to diagnosis and treatment of patients with suspected sleep apnea. Am J Respir Crit Care Med 2004;169:668-72.

14. Rotenberg B, George C, Sullivan K, et al. Wait times for sleep apnea care in Ontario: A multidisciplinary assessment. Can Respir J 2010;17:170-4.

15. Pendharkar SR, Bischak DP, Rogers $P$, et al. Using patient flow simulation to improve access at a multidisciplinary sleep centre. J Sleep Res 2015;24:320-7.

16. Allen AJ, Amram O, Tavakoli $\mathrm{H}$, et al. Relationship between travel time from home to a regional sleep apnea clinic in British Columbia, Canada, and the severity of obstructive sleep. Ann Am Thorac Soc 2016;13:719-23.

17. Chai-Coetzer CL, Antic NA, McEvoy RD. Identifying and managing sleep disorders in primary care. Lancet Respir Med 2015;3:337-9.

18. Sánchez-de-la-Torre M, Nadal N, Cortijo A, et al.; Respiratory Medicine Research Group. Role of primary care in the follow-up of patients with obstructive sleep apnoea undergoing CPAP treatment: a randomised controlled trial. Thorax 2015;70:346-52.

19. Kendzerska T, Gershon AS, Tomlinson G, et al. The effect of patient neighbourhood income level on the purchase of continuous positive airway pressure treatment among patients with sleep apnea. Ann Am Thorac Soc 2016;13:93-100.

20. Simon-Tuval T, Reuveni H, Greenberg-Dotan S, et al. Low socioeconomic status is a risk factor for CPAP acceptance among adult OSAS patients requiring treatment. Sleep 2009;32:545-52.

21. Law MR, Cheng L, Dhalla IA, et al. The effect of cost on adherence to prescription medications in Canada. CMAJ 2012;184:297-302.

22. Lee A, Morgan S. Cost-related nonadherence to prescribed medicines among older Canadians in 2014: a cross-sectional analysis of a telephone survey. CMAJ Open 2017;5:E40-4.

23. Sin DD, Mayers I, Man GC, et al. Long-term compliance rates to continuous positive airway pressure in obstructive sleep apnea: a population-based study. Chest 2002;121:430-5.

24. Morgan SG, Law M, Daw JR, et al. Estimated cost of universal public coverage of prescription drugs in Canada. CMAJ 2015;187:491-7.

25. Hayes SM, Murray S, Castriotta RJ, et al. (Mis) perceptions and interactions of sleep specialists and generalists: Obstacles to referrals to sleep specialists and the multidisciplinary team management of sleep disorders. J Clin Sleep Med 2012;8:633-42. 
26. Sleep study. Baltimore: U.S. Centers for Medicare and Medicaid Services. Available: https://www.medicare.gov/coverage/sleep-study.html (accessed 2017 Apr. 3).

27. Special payment rules for items furnished by DMEPOS suppliers and issuance of DMEPOS supplier billing privileges. Baltimore: U.S. Centers for Medicare and Medicaid Services. Available: https://www.cms.gov/medicare/providerenrollment-and-certification/medicareprovidersupenroll/downloads/dmepossupplierstandards.pdf (accessed 2017 Apr. 3).

28. Woods CE, Usher KJ, Jersmann $\mathrm{H}$, et al. Sleep disordered breathing and polysomnography in Australia: trends in provision from 2005 to 2012 and the impact of home-based diagnosis. J Clin Sleep Med 2014;10:767-72.

29. Steier J, Martin A, Harris J, et al. Predicted relative prevalence estimates for obstructive sleep apnoea and the associated healthcare provision across the UK. Thorax 2014;69:390-2.
30. Hanes CA, Wong KK, Saini B. Consolidating innovative practice models: the case for obstructive sleep apnea services in Australian pharmacies. Res Social Adm Pharm 2015;11:412-27.

31. Standards for adult respiratory and sleep services in New Zealand. Wellington (New Zealand): Ministry of Health; 2004. Available: https://www.health. govt.nz/publication/standards-adult-respiratory-and-sleep-services-new-zealand (accessed 2017 Apr. 3).

32. Almeida FR, Bansback N. Long-term effectiveness of oral appliance versus CPAP therapy and the emerging importance of understanding patient preferences. Sleep 2013;36:1271-2.

33. Trenaman L, Sadatsafavi M, Almeida F, et al. Exploring the potential costeffectiveness of patient decision aids for use in adults with obstructive sleep apnea: a case study. Med Decis Making 2015;35:671-82.
Competing interests: Sachin Pendharkar reports personal fees outside the submitted work from VitalAire Canada, Ltd. for interpreting home sleep apnea tests, and from RHS Canada for providing continuing education on obstructive sleep apnea. Najib Ayas and Debra Morrison are on the medical advisory board for BresoTEC Inc., a Canadian company that makes an ambulatory device to detect sleep apnea. Debra Morrison reports receiving a grant jointly funded by the Canadian Institutes of Health Research and Phillips. No other competing interests were declared.

This article was solicited and has been peer reviewed.

Affiliations: Departments of Medicine and Community Health Sciences (Pendharkar), Cumming School of Medicine, University of Calgary, Calgary, Alta.; Departments of Medi- cine (Povitz, George) and Epidemiology, and Biostatistics (Povitz), Schulich School of Medicine \& Dentistry, Western University London, Ont.; School of Population and Public Health (Bansback), Faculty of Medicine, University of British Columbia, Vancouver, BC; Department of Medicine (Morrison), Dalhousie University, Halifax, NS; Sleep Disorders Program and Department of Medicine (Ayas), University of British Columbia, Vancouver, BC

Contributors: Najib Ayas, Nick Bansback, Sachin Pendharkar and Marcus Povitz contributed to the conception and design of the work. Najib Ayas, Charles George, Debra Morrison, Sachin Pendharkar and Marcus Povitz contributed to acquiring, analyzing and interpreting the data. Sachin Pendharkar drafted the manuscript and Najib Ayas, Nick Bansback, Charles George, Debra Morrison and Marcus Povitz revised the work critically for important intellectual content.
All of the authors gave final approval of the version to be published and agree to be accountable for all aspects of the work.

Funding: The Canadian Sleep and Circadian Network is supported by the Canadian Institutes of Health Research Community Development Grant. The sponsor had no part in the development or writing of this manuscript.

Acknowledgements: The authors thank Dr. Patrick Hanly for review of an earlier draft of this manuscript, and Drs. Eleni Gianoulli, Caroline Minville, Robert Skomro and Kathy Spurr, RRT for providing information on costs and public funding of testing and treatment for obstructive sleep apnea across Canada. Nick Bansback is a Canadian Institutes of Health Research New Investigator.

Correspondence to: Sachin Pendharkar, sachin.pendharkar@ucalgary.ca 